\author{
BARBARA BUKOWSKA-BELNIAK \\ MACIEJ DWORNIK \\ ANDRZEJ LEŚNIAK
}

\title{
ANALYSIS \\ OF ANNUAL TEMPERATURE DISTRIBUTION \\ INSIDE THE EXPERIMENTAL EMBANKMENT
}

Abstract

Keywords

Citation Computer Science 18(4) 2017: 385-397 were estimated. of soil

The aim of this paper is to establish a method for determining mean temperatures inside a soil embankment using the changes of air temperature in the annual cycle as well as an analysis of temperature distribution inside an experimental embankment from August 2015 to September 2016. The analysis was carried out in order to interpret the results of flood experiments performed on the experimental embankment. A reference was obtained for yearly temperature changes in the embankment at various depths. A simplified model of temperature changes depending on depth was made. The model parameters that can be used for modeling temperatures in the embankment during the experiments

annual temperature analysis, experimental embankment, thermal parameters 


\section{Introduction}

The method for determining mean temperatures inside a soil embankment using changes in air temperature in the annual cycle is presented in the article. Another objective is estimating the thermal parameters of the soils from which the embankment was built using the measured air temperatures and temperatures registered by the sensors installed inside the embankment. This is a typical inverse problem that can be solved by the estimation procedure using a simplified geometric model.

Many approaches to determining thermal parameters like heat transfer coefficient, thermal conductivity, or heat flux in 2D and 3D models [14] have been developed so far. For example, descriptions of the estimation methods for thermal conductivity can be found in $[1,9,13]$. An estimation of the heat transfer coefficient was presented in $[4,11]$.

Temperature measurements inside the existing embankments over a long cycle (minimum one-year) at different depths in a dense grid are rare. The results described here are pioneering because they investigate the effect of temperature changes on the annual cycle in relation to inflow. In addition, during an analysis based on measured temperatures, the thermal parameters of the soil were estimated. The goals were achieved using an analysis of temperature distribution inside an experimental embankment from August 2015 to September 2016.

The experimental embankment was built for monitoring inner processes using system of sensors developed during the ISMOP project $[8,16]$. The embankment is 200 meters long, 50 meters wide, and 4.5 meters tall. An additional system of reference sensors was installed in three cross-sections and along the embankment in two loops of optic fibers. This system registers several physical parameters such as temperature, pore pressure, displacement, and tension [15]. The system also registers such weather parameters as air temperature, atmospheric pressure, rain total, and wind direction.

A measurement system of data collection, transmission, and visualization was made to monitor the embankment's behavior during flooding experiments [2]. The embankment can be filled with water from the Vistula River according to any scenario via pumps. Numerical modeling, which is compared to the recordings of the sensors, have been made [6]. Numerical modeling examines the stability of the embankment [7], impact of the daily changes, and level of inflow water during flooding experiments.

The validation of the numerical models is based on a few initial experiments. The changes of temperature distribution inside the embankment is a considerably complex issue due to heat flow from all directions as well as the influence of air temperature, solar radiation, surface temperature, vegetation, etc. In this work, it was decided to analyze the temperature of the embankment on an annual basis in order to create simple initial thermal conditions for the numerical models. To interpret the results of the experiments, we need to have a reference background of the full-year changes. The parameters describing the thermal processes for the three sections (western embankment built from one type of material) were estimated. The time of year in which the best conditions for leak location using the temperature sensors was also determined. 


\section{Construction of experimental embankment}

The embankment is divided into a few sections, each consisting of a different type of soil [5]. Figure 1 shows an aerial photo of the experimental embankment (photo: Sonia Bazan, http://losa.tech) and scheme of the division into sections. The western part of the embankment consists of one type of material $(A)$, and the eastern part consists of three types of material $(B, C$, and $D)$. The bends of the embankment consist of the $E$ material type. The experimental embankment is provided with a reference sensor system that is installed in three cross-sections (northern, central, and southern). This sensor system registers the following parameters: temperature, pore pressure, tension, and displacement.

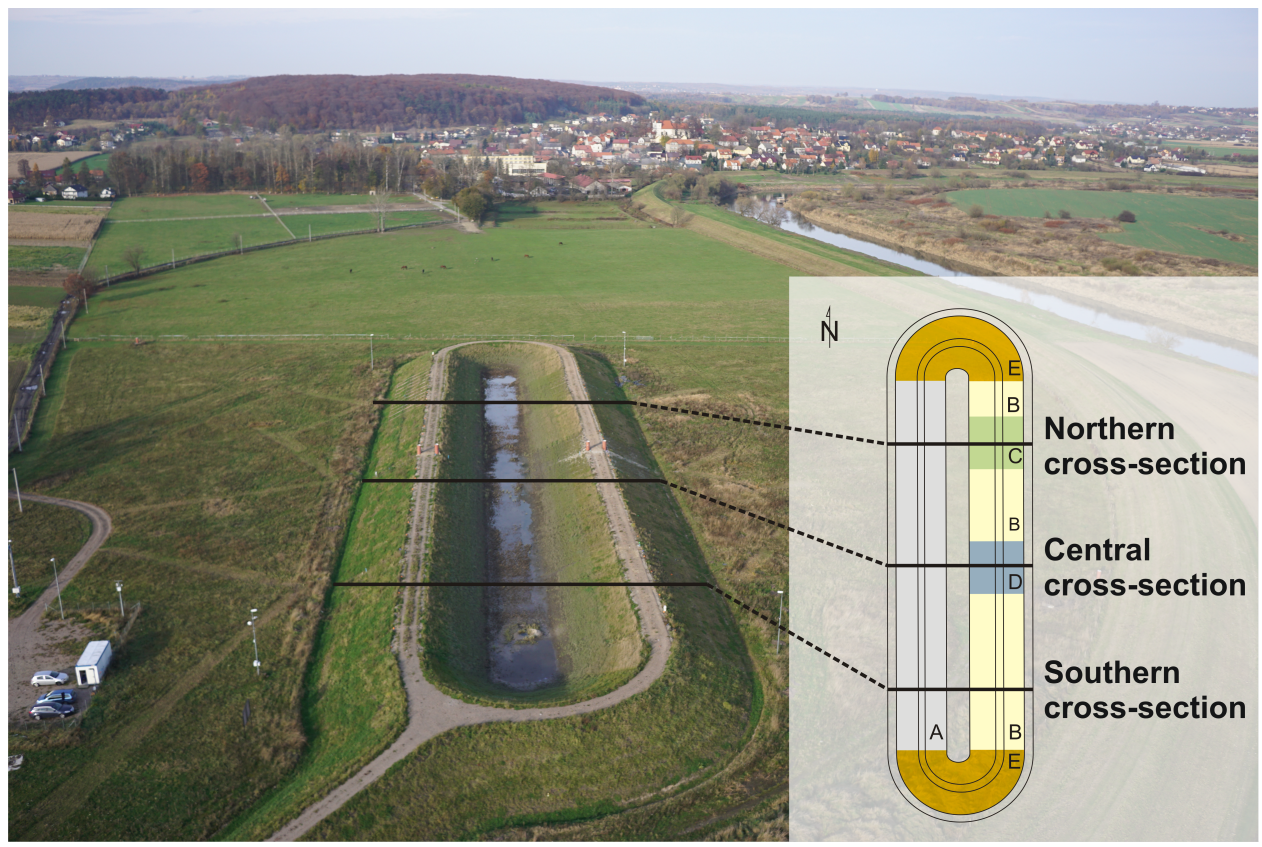

Figure 1. Experimental embankment (fot. Sonia Bazan, http://losa.tech) with scheme of division into sections.

The western part of the embankment is symmetrical, and the eastern part is asymmetrical (with a smaller angle of waterside slope). Figure 2 shows the temperature sensor location in all of the reference cross-sections. These sensors vary in distance from the surface, which enables an analysis of temperature variation at each depth. The UT sensors measure temperature and pore pressure, and the SV sensors measure temperature and tension.

In the northern $(\mathrm{N})$ and southern $(\mathrm{S})$ cross-sections, ten reference temperature sensors were installed: six in the western part (W) and six in the eastern part (E). 

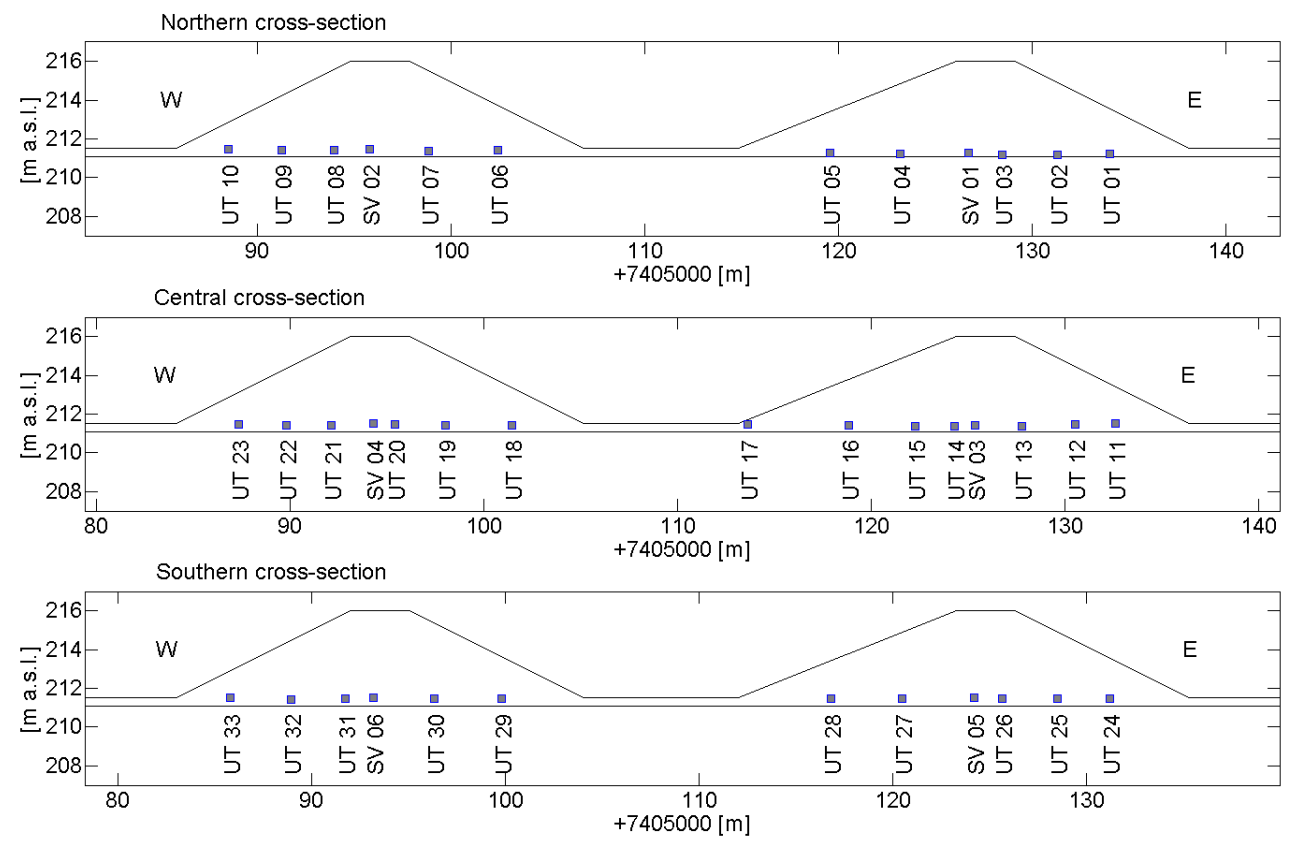

Figure 2. Location of reference sensors based on geodetic coordinates.

In the central cross-section (C), 15 sensors were installed: 7 in the western part and 8 in the eastern part.

\section{Temperature measurements}

Figure 3 shows the variation of temperatures of all of the temperature reference sensors as well as the air temperature for one year (August 2015 - September 2016). For our analysis, we only chose the reference sensor system due to its operation for the entire year. Additional sensors (about 1000 units) were installed in the embankment about half a year later than the reference system.

The conclusions drawn from Figure 3 are straightforward. The highest variation of temperature is observed by the sensor closest to the surface. It also can be observed that the amplitude of the temperature decreases as the depth increases, and the phase shift increases a greater depths. Twice a year, all of the temperatures have a similar value (in October and April). Sensor UT 17, which is located about $20 \mathrm{~cm}$ below the surface, is the most-sensitive to any changes in air temperature. On this basis, it was decided to prepare a simplified model of thermal changes depending on the depth. Then, for the prepared model, the parameters of the model were estimated. 


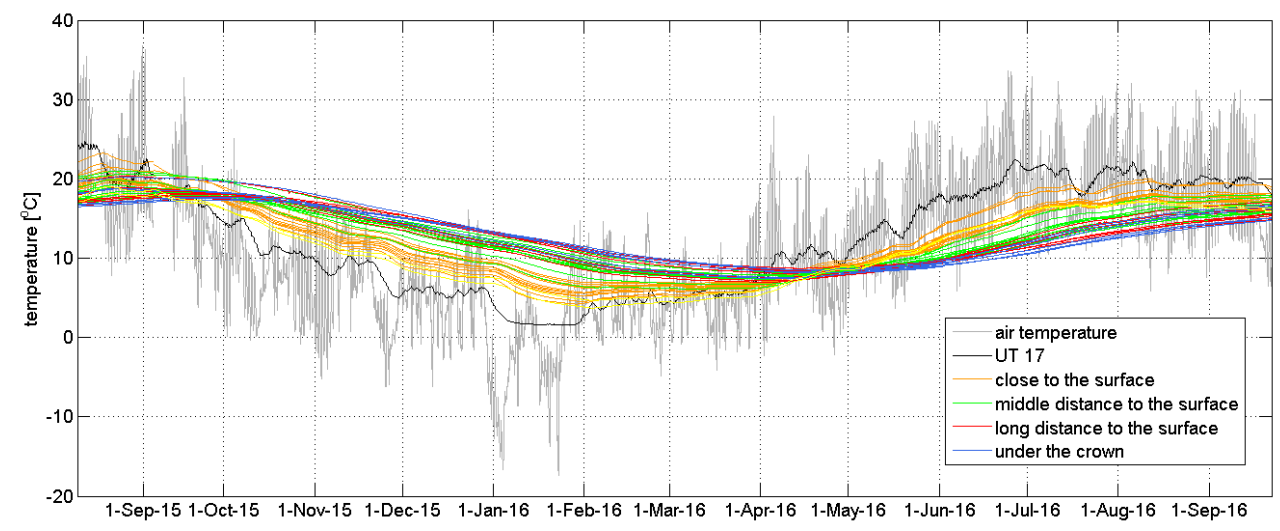

Figure 3. Temperatures $\left[{ }^{\circ} \mathrm{C}\right]$ in all reference point sensors.

\section{Theory}

The equation below presents the temperature of the Earth's surface $t$ as a periodic function of period $T$ depending of time $\tau$ with the assumption that the Earth is a horizontal half-space [3]:

$$
t(0, \tau)=A_{0}+A \cos \left(\frac{2 \pi}{T} \tau\right)
$$

where: $A$ is an amplitude of the changes in temperature of Earth's surface, and $A_{0}$ is the average annual temperature.

Then, for depth $h$ in the soil with thermal diffusivity $\alpha=a^{2}$, the temperature is also a periodic function depending of time $\tau$ :

$$
t(h, \tau)=A_{0}+A \exp \left(-\frac{h}{a} \sqrt{\frac{\pi}{T}}\right) \cos \left(\frac{2 \pi}{T}\left(\tau-\frac{h}{2 a} \sqrt{\frac{T}{\pi}}\right)+\varphi\right)
$$

where: $\varphi$ is the phase of temperature changes.

Thermal diffusivity $\alpha\left[\mathrm{m}^{2} / \mathrm{s}\right]$ is the thermal conductivity divided by the specific heat capacity at constant pressure [10].

$$
\alpha=\frac{k}{\rho c_{p}}
$$

where: $k$ is thermal conductivity $[\mathrm{W} /(\mathrm{m} \cdot \mathrm{K})], \rho$ is density $\left[\mathrm{kg} / \mathrm{m}^{3}\right]$, and $c_{p}$ is specific heat capacity $[\mathrm{J} /(\mathrm{kg} \cdot \mathrm{K})]$.

As seen from Formula 2, the period of change remains constant, and the amplitude decreases exponentially with increasing depth proportional to the increase in 
depth of the time delay. The amplitude of the temperature fluctuations of depth $h$ represents factor:

$$
A \exp \left(-\frac{h}{a} \sqrt{\frac{\pi}{T}}\right)
$$

It is easy to see that it is the greater, when the greater is amplitude of the surface temperature changes $A$ and the period of change of the temperature. It decreases with the less depth $h$ and the higher temperature conductivity.

From here, we can make some conclusions. For example, comparing the amplitude changes at depths of $h_{1}$ and $h_{2}$ and the periods of changes of $T_{1}$ and $T_{2}$, we obtain:

$$
\frac{h_{1}}{h_{2}}=\frac{\sqrt{T_{1}}}{\sqrt{T_{2}}}
$$

which shows, for example, that the depth at which annual temperature variation practically disappears is about 19 times greater than the depth where the daily temperature fluctuations disappear. A similar conclusion can be drawn from the phase analysis, the time after which extreme temperature changes will be achieved is:

$$
\tau=\frac{h}{2 a} \sqrt{\frac{T}{\pi}}
$$

In the case of the measurements in the experimental embankment, we have the measurements at two points at depths $h_{1}$ and $h_{2}$. These can be used for estimating the distribution model:

$$
t\left(h_{i}, \tau\right)=A_{0}+A \exp \left(-\frac{h_{i}}{a} \sqrt{\frac{\pi}{T}}\right) \cos \left(\frac{2 \pi}{T}\left(\tau-\frac{h_{i}}{2 a} \sqrt{\frac{T}{\pi}}\right)+\varphi\right)
$$

\section{Estimation of model parameters}

The determination value of the temperature inside the embankment could be possible using Equation 2. Before calculation, it is necessary to estimate the values of the model parameters. The temperature inside the embankment depends on four thermal parameters:

- $A_{0}$ - mean temperature at depth $h=0 \mathrm{~m}$;

- $A$ - amplitude of temperature at depth $h=0 \mathrm{~m}$;

- $a$ - is square root of thermal diffusivity $\alpha$;

- $\varphi$ - phase shift.

The values of these parameters were estimated separately for each sensor. The estimation of the parameters was done for the simplified form of Equation 2:

$$
t(\tau, h)=A_{0}+A \exp \left(w_{1} c \tau\right) \cdot \cos \left(w_{2} \tau+w_{1} c+\varphi\right)
$$

where: $w_{1}=-h \sqrt{\pi / T} ; w_{2}=2 \pi / T ; c=1 / a=1 / \sqrt{\alpha}$ 
The embankment is not a horizontal half-space, so depth $h$ was replaced by the distance from the sensor to the nearest point of the ground surface. Period $T$ is assumed to be equal to one year. The estimation was done using cftool available in MathWorks MatLAB 2014 software [12]. This tool allows us to estimate a model's parameters for any equation. The estimation is based on the minimized following form:

$$
\sum_{n=1}^{N}\left(T_{n}^{\text {observed }}-T\left(h, A, A_{0}, \alpha, \varphi\right)_{n}^{\text {estimated }}\right)^{2}=\min
$$

where $N$ - number of temperature observations for temperature sensor.

The values of the estimated parameters are shown in Figure 4. The amplitude of temperature $A$ increases with a decrease in distance between a sensor and the ground surface. This relationship suggests that the distance to the ground surface should be smaller than calculated. It could be the effect that the assumption of a flat ground surface is not fulfilled. Soil in the embankment has a larger surface of heat transfer with air than a flat half-space. Also, thermal diffusivity increases with greater distance to the ground surface. On all the plots in Figure 4, the differences between the cross-sections were not clearly visible. Only phase shift (Fig. 4c) for the southern cross-section seems to decrease slower with depth. This could be an effect of the sandy lens inside the embankment.

a)

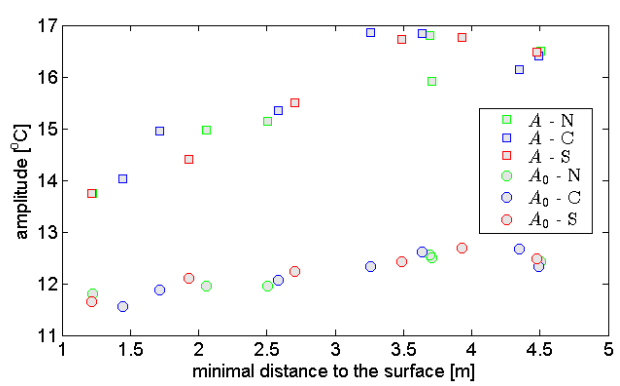

c)

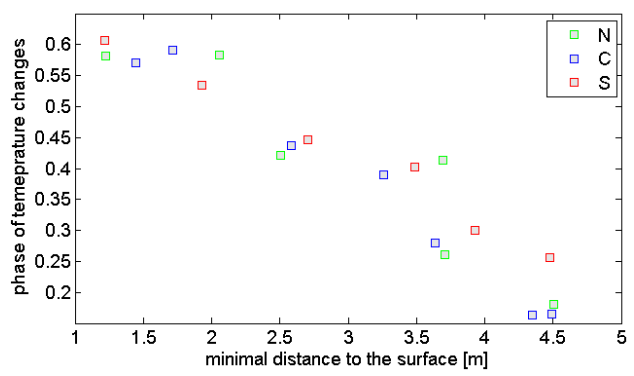

b)

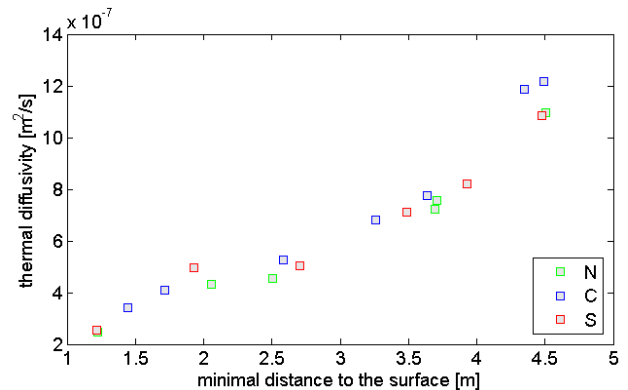

d)

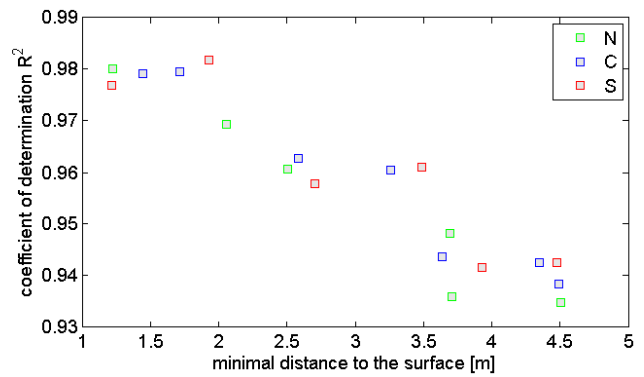

Figure 4. Estimated values of parameters: a) amplitudes $A$ and $A_{0}$; b) thermal diffusivity $\alpha$; c) phase of temperature changes $\varphi$; d) coefficient of determination $R^{2}$. 
Table 1 presents the distance to the surface and calculated coefficient of determination $R^{2}$ for each sensor in the western embankment. $R^{2}$ is the square of the correlation between the response values and the predicted response values given in Equation 10 [12].

$$
R^{2}=\frac{\sum_{n=1}^{N}\left(T_{n}^{\text {estimated }}-<T^{\text {observed }}>\right)^{2}}{\sum_{n=1}^{N}\left(T_{n}^{\text {observed }}-<T^{\text {observed }}>\right)^{2}}
$$

where:

$$
\begin{aligned}
N & - \text { number of observation, } \\
T^{\text {observed }} & \text { - measured temperature, } \\
T^{\text {estimated }} & \text { - estimated temperature, } \\
<> & - \text { mean value. }
\end{aligned}
$$

\begin{tabular}{|c|c|c|c|c|c|c|c|c|}
\hline \multicolumn{9}{|c|}{ Cross-section } \\
\hline \multicolumn{3}{|c|}{$\mathrm{N}$} & \multicolumn{3}{|c|}{$\mathrm{C}$} & \multicolumn{3}{|c|}{$\mathrm{S}$} \\
\hline sensor & distance & $R^{2}$ & sensor & distance & $R^{2}$ & sensor & distance & $R^{2}$ \\
\hline UT6 & 2.06 & 0.969 & UT18 & 1.71 & 0.980 & UT29 & 1.93 & 0.982 \\
\hline UT7 & 3.69 & 0.948 & UT19 & 3.26 & 0.961 & UT30 & 3.49 & 0.961 \\
\hline SV2 & 4.51 & 0.935 & UT20 & 4.35 & 0.943 & SV6 & 4.48 & 0.942 \\
\hline UT8 & 3.71 & 0.936 & SV4 & 4.49 & 0.938 & UT31 & 3.93 & 0.942 \\
\hline UT9 & 2.50 & 0.961 & UT21 & 3.64 & 0.944 & UT32 & 2.71 & 0.958 \\
\hline UT10 & 1.22 & 0.980 & UT22 & 2.58 & 0.963 & UT33 & 1.22 & 0.977 \\
\hline & & & UT23 & 1.44 & 0.979 & & & \\
\hline
\end{tabular}

Table 1

Minimal distances $[\mathrm{m}]$ to the surface from each sensor.

The values of $R^{2}$ decrease with increasing distance to the ground surface. This could again be the effect of a non-flat half-space. Points with the greatest distance to the surface are just under the crown of the embankment and have almost the same distance from both the embankment and crown to the ground surface.

\section{Temperature analysis}

Due to the simplified theoretical model, an analysis was only performed for the western symmetrical part of the embankment (which consists of one type of soil). All sensors presented in Table 1 are located in this part of the embankment. Figure 5 presents a comparison of the temperatures measured in the northern, central, and southern cross-sections in the western embankment at similar minimal distances to the surface. Figures a) through f) visualize the measurements for the sensors (from deepest to shallowest). 
a)

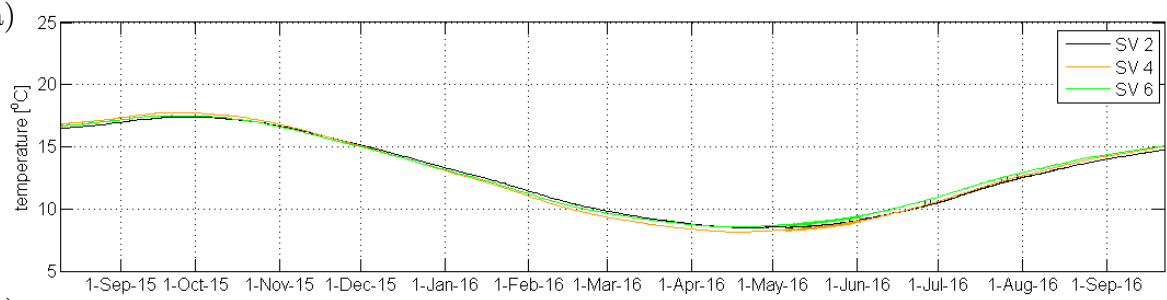

b)

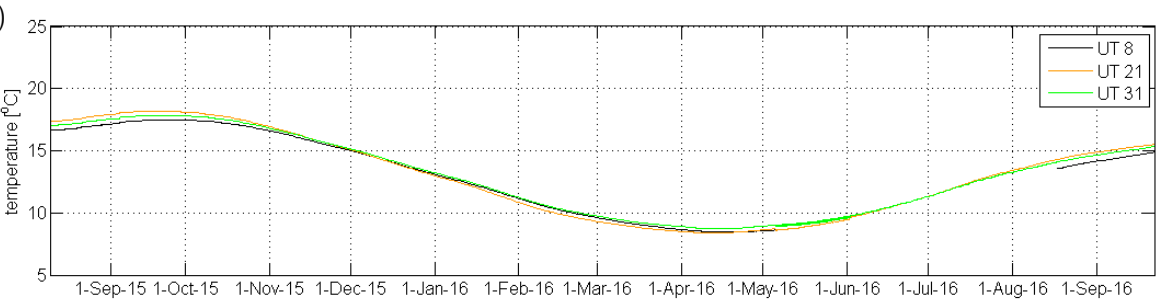

c)

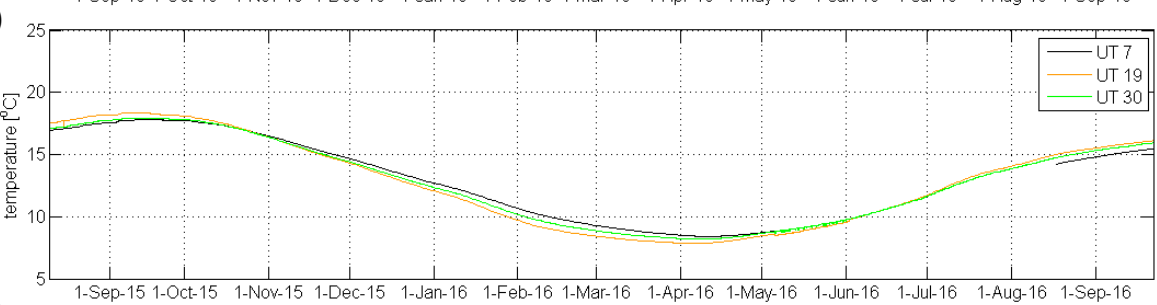

d)

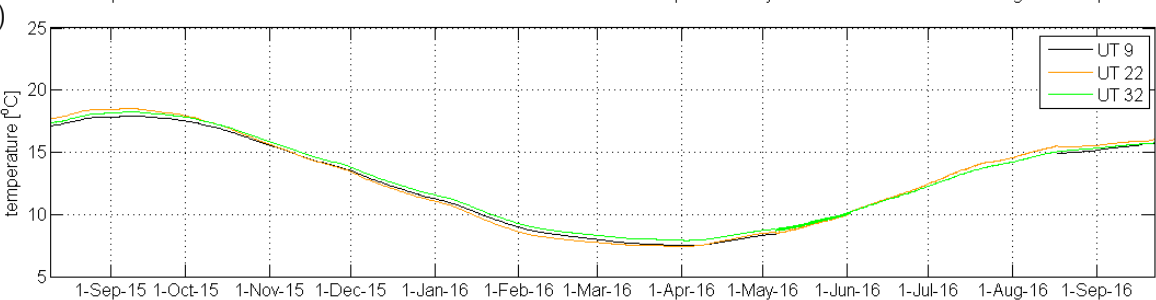

e)

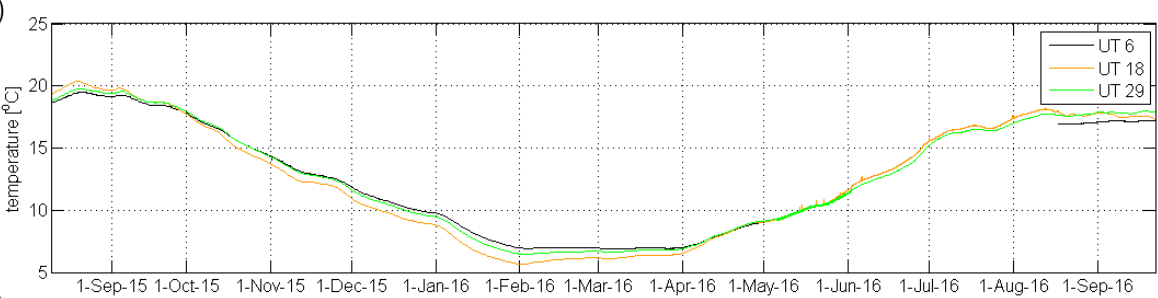

f)

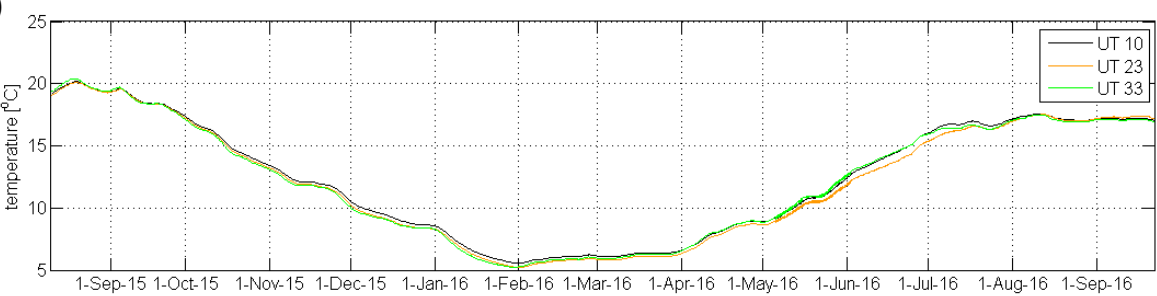

Figure 5. Temperature $\left[{ }^{\circ} \mathrm{C}\right]$ in sensors on similar minimal distance to surface. 
In Figure 5, the sensors are ordered by minimal distance to the surface in each cross-section (N, C, and S):

a) SV2 (N, $4.51 \mathrm{~m})$, SV4 (C, $4.49 \mathrm{~m})$ and SV6 (S, $4.48 \mathrm{~m})$ sensors

b) UT8 $(\mathrm{N}, 3.71 \mathrm{~m})$, UT21 (C, $3.64 \mathrm{~m})$ and UT31 (S, $3.93 \mathrm{~m})$ sensors

c) UT7 (N, $3.69 \mathrm{~m})$, UT19 (C, $3.26 \mathrm{~m})$ and UT30 (S, $3.49 \mathrm{~m})$ sensors

d) UT9 (N, $2.50 \mathrm{~m})$, UT22 (C, $2.58 \mathrm{~m})$ and UT32 (S, $2.71 \mathrm{~m})$ sensors

e) UT6 (N, $2.06 \mathrm{~m})$, UT18 (C, $1.71 \mathrm{~m})$ and UT29 (S, $1.93 \mathrm{~m})$ sensors

f) $\operatorname{UT} 10(\mathrm{~N}, 1.22 \mathrm{~m})$, UT23 (C, $1.44 \mathrm{~m})$ and UT33 (S, $1.22 \mathrm{~m})$ sensors

In the western part of the embankment, the SV2, SV4, and SV6 sensors are located the deepest, directly under the crown of the embankment (Fig. 5a). The minimal distance to the surface of these sensors is about $4.5 \mathrm{~m}$. The amplitude for these sensors is the smallest (about $9^{\circ} \mathrm{C}$ ). The maximum temperature occurred in September, and the minimum in April; so, the shift in time is greatest (about three months due to the sensors located with the lowest minimal distances to the surface). Sensors UT10, UT23, and UT 33 have the least distance to the surface. The temperatures registered by these sensors are visible in Figure $5 \mathrm{f}$ ). The distance to the surface is more than $1 \mathrm{~m}$. The amplitude for these sensors is the greatest (about $15^{\circ} \mathrm{C}$ ). Maximal temperatures were from July to August, and minimal from January to February. The temperature curve is not smooth; there are visible short-term variations caused by changes in air temperature.

Figure 5 allows for some conclusions. With increasing distance to the surface, the amplitude of the temperature decreases while the shift in time increases. The sensors located closest to the ground surface are more sensitive to short-term temperature fluctuations. The soil works like a low-pass filter, so the sensors located deeper register smoother curves with smaller amplitudes. For the sensors located deeper, thermal changes come later and are less intense than at shallower depths.

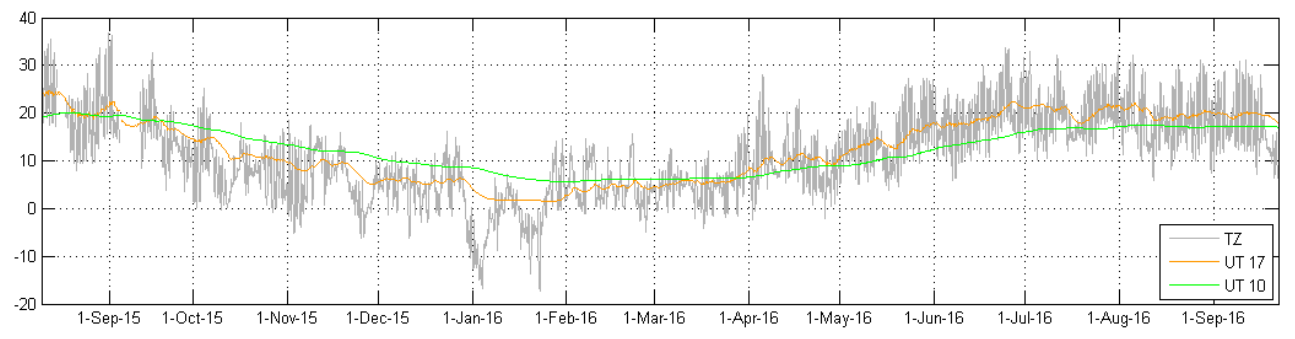

Figure 6. Temperature $\left[{ }^{\circ} \mathrm{C}\right]$ in UT17, UT10 sensors, and temperature of air (TZ).

Figure 6 shows how sensitive the sensor located closest to the surface is to air temperature. This figure presents temperatures registered by the UT10 $(1.22 \mathrm{~m})$ and UT17 $(0.2 \mathrm{~m})$ sensors as well as TZ - the air temperature at $2 \mathrm{~m}$ above the ground surface. The UT17 sensor responds to daily temperature changes with a delay of about 12 hours and a maximum of $0.5^{\circ} \mathrm{C}$ amplitude for these thermal changes. The 
UT10 sensor does not respond to daily changes but does respond to short-time trends of temperature variability.

\section{Conclusions and future work}

The estimated model parameters allow for the verification of the thermal parameters of the ground, which allow us to model temperature changes in the embankment during flood experiments and validate with real measured temperature values by the temperature sensors. The data used in the analysis partly comes from the period of flooding experiments (from June through September, 2016), so it can be disturbed by the water temperature in the embankment. Temperature changes during flooding experiments caused by water have a small influence on the temperature of the embankment as a whole. Also, the estimated parameters change according to depth.

A short-term interpretation of the temperature measurements is difficult because they are affected by air temperature, solar radiation, rain, etc. All of these external parameters should be known and taken into account, especially in the case of leak detection. An interpretation should be done with consideration of the background temperature.

Using the presented analysis, it will be possible to prepare a numerical model for the initial temperature of the experiment performed during a given period of the year. The greatest differences in temperatures will be in the warm spring. The preparation of flooding experiments on the embankment during the hot spring when the high temperature differences that occur can lead to an increased heat flow inside the embankment. This will be registered by the temperature sensors. In the case of anomalous temperature distribution, it will be able to detect deviations from the models that will lead to the detection of leakage and the associated risk of an embankment's damage. With a year-round analysis, we are able to apply monitoring throughout the year.

In practice, the presented analyses can also be used for different types of soil to determine their thermal parameters. Each point at a given depth in the annual cycle has a thermal background. A definition of this thermal background will allow for analysis and interpretation of the measured temperature under abnormal conditions. It is necessary to record the full annual temperature cycle for a specific type of soil of a given structure to correctly interpret the temperature at a point with reference to the thermal background.

\section{Acknowledgements}

This work was partly supported by the National Center of Research and Development (NCBiR), Poland, project PBS1/B9/18/2013 (no. 180535). This work was partly supported by the AGH University of Science and Technology, Faculty of Geology, Geophysics and Environmental Protection, as a part of statutory project No. 11.11.140.613. 


\section{References}

[1] Artyukhin E.A.: Reconstruction of the thermal conductivity coefficient from the solution of the nonlinear inverse problem, Journal of Engineering Physics, vol. 41(4), pp. 1054-1058, 1981.

[2] Balis B., Brzoza-Woch R., Bubak M., Kasztelnik M., Kwolek B., Nawrocki P., Nowakowski P., Szydlo T., Zielinski K.: Holistic approach to management of IT infrastructure for environmental monitoring and decision support systems with urgent computing capabilities, Future Generation Computer Systems, vol. 79(1), pp. 128-143, 2018. https://doi.org/10.1016/j.future.2016.08.007.

[3] Bilski E.: Geofizyka. Oficyna Wydawnicza Politechniki Warszawskiej, Warszawa, 1966.

[4] Chen W.L., Yang Y.C., Lee H.L.: Inverse problem in determining convection heat transfer coefficient of an annular fin, Energy Conversion and Management, vol. 48(4), pp. 1081-1088, 2007.

[5] Chuchro M., Lupa M., Szostek K., Bukowska-Belniak B., Leśniak A.: Detekcja potencjalnych anomalii pomiarów parametrów w wale przeciwpowodziowym, Studia Informatica, vol. 37(1), pp. 175-185, 2016.

[6] Chuchro M., Franczyk A., Dwornik M., Leśniak A.: A Big Data processing strategy for hybrid interpretation of flood embankment multisensor data, Geology, Geophysics and Environment, vol. 42(3), pp. 269-277, 2016.

[7] Dwornik M., Krawiec K., Pięta A., Leśniak A.: Numerical and experimental stability analysis of earthen levees. In: IAMG 2015: the 17th annual conference of the International Association for Mathematical Geosciences: Freiberg, Germany, pp. 857-864, 2015.

[8] ISMOP: project website. http://www.ismop.edu.pl.

[9] Jurkowski T., Jarny Y., Delaunay D.: Estimation of thermal conductivity of thermoplastics under moulding conditions: an apparatus and an inverse algorithm, International Journal of Heat and Mass Transfer, vol. 40(17), pp. 4169-4181, 1997.

[10] Lide D.R.: CRC Handbook of Chemistry and Physics (90th ed.), CRC Press, Boca Raton, Florida, 2009.

[11] Liu F.B.: A hybrid method for the inverse heat transfer of estimating fluid thermal conductivity and heat capacity, International Journal of Thermal Sciences, vol. 50(5), pp. 718-724, 2011.

[12] MATLAB: version 8.3.0.532 (R2014a). The MathWorks Inc., Natick, Massachusetts, 2014.

[13] Mierzwiczak M., Kołodziej J.A.: The determination temperature-dependent thermal conductivity as inverse steady heat conduction problem, International Journal of Heat and Mass Transfer, vol. 54(4), pp. 790-796, 2011.

[14] Mohebbi F., Sellier M.: Estimation of thermal conductivity, heat transfer coefficient, and heat flux using a three dimensional inverse analysis, International Journal of Thermal Sciences, vol. 99, pp. 258-270, 2016. 
[15] Stanisz J., Borecka A., Leśniak A., Zieliński K.: Wybrane systemy monitorujące obwałowania przeciwpowodziowe - Selected levee monitoring systems, Przeglad Geologiczny, vol. 62, pp. 699-703, 2014.

[16] Stanisz J., Korzec K., Borecka A.: ISMOP Project (IT System of Levee Monitoring) as an example of integrated monitoring of levee, Geology, Geophysics and Environment, vol. 41(1), pp. 137-139, 2015.

\section{Affiliations}

\section{Barbara Bukowska-Belniak}

AGH University of Science and Technology, Faculty of Geology, Geophysics and Environmental Protection, al. A. Mickiewicza 30, 30-059 Kraków, Poland, bukowska@agh.edu.pl

\section{Maciej Dwornik}

AGH University of Science and Technology, Faculty of Geology, Geophysics and Environmental Protection, al. A. Mickiewicza 30, 30-059 Kraków, Poland

\section{Andrzej Leśniak}

AGH University of Science and Technology, Faculty of Geology, Geophysics and Environmental Protection, al. A. Mickiewicza 30, 30-059 Kraków, Poland

Received: 31.12 .2016

Revised: 18.05 .2017

Accepted: 31.07 .2017 